\title{
Expected efficiency of selection for growth in a French beef cattle breeding scheme. I. Multistage selection of bulls used in artificial insemination
}

\author{
F Phocas, JJ Colleau, F Ménissier \\ Institut national de la recherche agronomique, station de génétique \\ quantitative et appliquée, 78352 Jouy-en-Josas cedex, France
}

(Received 24 February 1994; accepted 18 October 1994)

\begin{abstract}
Summary - Genetic improvement of beef cattle for growth traits implies selection on both direct and maternal effects through on-farm and station individual and progeny performance tests. To optimize the use of these tools, a French selection scheme of artificial insemination (AI) bulls is modelled, including its main components, ie 2 kinds of station performance tests and 2 kinds of progeny tests (farm and station). Three breeding objectives are derived in order to represent the heterogeneity of production systems: $H \mathrm{~s}$ for suckler herds, $H \mathrm{f}$ for suckler-fattening herds and an average objective $\mathrm{Hg}$ considered as the most realistic for the whole breed. These objectives include direct and maternal genetic effects on weaning weight and direct effects on final weight. Economic, demographic and genetic parameters are derived for the Limousin breed. Multistage selection procedures are algebraically optimized by finding selection thresholds which maximize response for the breeding objectives. The current scheme appears to be more efficient for $H \mathrm{f}$ than for $H$ s. However, whatever the objective, maternal genetic response is expected to be slightly negative, due to a negative correlation between direct and maternal genetic effects. Standard deviations of genetic responses are calculated to take into account some uncertainty on estimates of genetic parameters. With a $95 \%$ confidence interval, maternal genetic response could be positive. An alternative to this complex scheme is considered, using only one kind of station performance test and the on-farm progeny test. The increase of on-farm progeny test capacity reduces the value of station progeny test for selecting AI bulls, at least when only direct and maternal effects on growth traits are considered. For the simplified scheme, maternal response is expected to be positive, though uncertain due to a large standard deviation.
\end{abstract}

beef cattle / breeding objective / growth / maternal effects / sampling variance 
Résumé - Prédiction de l'efficacité d'un schéma de sélection français sur la croissance en race bovine allaitante. I. Sélection par étapes des taureaux destinés à l'insémination artificielle. En races bovines allaitantes, l'amélioration génétique des caractères de croissance passe par la sélection des effets directs et des effets maternels par contrôles individuel et de descendance, en ferme et en station. Pour optimiser l'emploi de ces outils, un schéma de sélection français des taureaux d'IA a été modélisé en considérant ses principales complexités : 2 types de stations de contrôle individuel et 2 types de contrôles de descendance (en ferme et en station). Afin de prendre en compte l'hétérogénéité des systèmes de production, 3 objectifs de sélection ont été établis : $\mathrm{Hs}$ pour les élevages naisseurs, $\mathrm{H} f$ pour les élevages naisseurs-engraisseurs et un objectif moyen $\mathrm{H} g$, considéré comme le plus réaliste pour l'ensemble des troupeaux de la race. Ces objectifs comportent les effets directs et maternels sur le poids au sevrage ainsi que les effets directs sur le poids final d'engraissement. Les paramètres économiques, démographiques et génétiques utilisés correspondent à la situation de la race Limousine. La sélection à plusieurs étapes est optimisée algébriquement en calculant les seuils de troncature qui maximisent la réponse sur l'objectif de sélection. Le schéma de sélection semble plus efficace pour un objectif naisseurengraisseur que pour un objectif naisseur. Toutefois, quel que soit l'objectif, la réponse sur les effets maternels est légèrement négative en raison de l'antagonisme génétique entre effets directs et maternels. L'incertitude sur les estimées des paramètres génétiques est prise en compte en calculant les écarts types de réponses à la sélection. Si l'on considère l'intervalle de confiance à 95\%, une réponse positive pourrait être obtenue sur les effets maternels. Un schéma simplifié a été étudié, n'utilisant qu'un seul type de station de contrôle individuel ainsi que le seul contrôle sur descendance en ferme. Dans une perspective d'accroissement de la capacité d'évaluation sur descendance en ferme, il apparâ̂t qu'une sélection de taureaux d'IA sur descendance en station perd de son intérêt technique, du moins quand seuls les effets directs et maternels sur la croissance sont considérés. En schéma simplifié, une réponse positive est espérée sur les effets maternels, mais n'est pas assurée, en raison de l'importance de l'écart type de la réponse.

bovin allaitant / objectif de sélection / croissance / effets maternels / variance d'échantillonnage

\section{INTRODUCTION}

Beef cattle breeding in France takes 2 kinds of traits into account (Ménissier and Frisch, 1992): beef traits (growth, morphology, feed efficiency, carcass quality) and maternal performance (fertility, ease of calving, mothering ability). From a national viewpoint, the relative economic importance of these traits depends on the relative proportion of suckler herds and suckler-fattening herds. In a suckler herd, calves are sold at weaning (around 7-8 months) to be partly fattened outside France, in a suckler-fattening herd, calves are reared to slaughter at around 14-18 months. Over the last 10 years, the decrease of industrial crossing and the need for reducing production costs and labor requirements have led to more emphasis being placed on beef cow productivity (Ménissier, 1988). This has led to the introduction of specific evaluation procedures for maternal performance into French beef cattle breeding schemes (Ménissier et al, 1982).

Modelling and optimization of these breeding schemes imply taking into account several points that are unusual in dairy cattle schemes: multistage selection with 
independent culling levels on highly correlated traits; the heterogeneity of genetic levels among newborn candidates for selection due to the joint use of natural service (NS) and artificial insemination (AI) bulls; and the large uncertainty in estimates of certain genetic parameters, especially concerning correlations between direct and maternal effects.

The purpose of this paper is to analyze the predicted efficiency of the current AI bull selection scheme for growth, when maternal effects are considered. This is an extension of previous work (Colleau and Elsen, 1988) which considered only selection on direct effects for final weight. The study uses the parameters and the scheme organisation of the Limousin breed, taken as a representative example of French beef cattle breeding schemes.

Three major questions are investigated in this first paper. 1) How can the AI bull multistage selection in the current breeding scheme be optimized? 2) Given the accuracies and sampling correlations of the estimated genetic parameters, what is the accuracy of predicted responses? 3) Should alternative breeding schemes be envisaged for AI bull selection? The objective of the next paper in this issue (Phocas et $a l, 1995)$ is to take into account both reproduction methods (AI and NS) and female selection paths. For both papers, theoretical problems of general interest are investigated. How can we calculate the accuracy of predicted responses? How can we calculate asymptotic genetic gains in heterogeneous populations?

\section{MATERIALS AND METHODS}

The meanings of abbreviations used in the text and tables are given in Appendix I.

\section{Deriving a relevant breeding objective}

The economic values of beef cattle production traits differ according to production systems and circumstantial parameters, as recalled by Doren et al (1985). Hence, the derivation of the selection objective should account for the existence of 2 main kinds of production herds, depending on how progeny are sold: at weaning in a suckler herd; and after fattening in a suckler-fattening herd. Calves were assumed to be sold at a constant age: $210 \mathrm{~d}$ at weaning (67\%) or $500 \mathrm{~d}$ after fattening $(33 \%)$. Only growth was considered in the present study. In order to distinguish the genetic influence of dam's suckling ability on calf growth from her genetic direct transmitting ability, a suckler herd breeding objective $(H \mathrm{~s})$ was derived, which includes maternal effects (M210) on weaning weight (W210) together with direct effects (A210). For suckler-fattening herds, the breeding objective $(H \mathrm{f})$ also took into account direct (A500) on final weight (W500). A combined objective $(\mathrm{Hg})$ was built from $H \mathrm{~s}$ and $H \mathrm{f}$ to represent the true economic objective of the breed. The economic weights of $\mathrm{Hg}$ were derived from the relative proportion of calves sold at weaning (2:3) compared to calves sold at $500 \mathrm{~d}(1: 3): H \mathrm{~g}=2 / 3 \mathrm{Hs}+1 / 3 \mathrm{Hf}$.

In order to maximize the profit for trait $i$ per animal sold, the partial derivative of profit with respect to a unit change in that trait was computed. This is called the economic margin $\left(a_{i}\right)$ for trait $i$. Direct and maternal expression of the same trait were considered as 2 different traits $j$ and $k$. Figures used for derivation of economic margins are presented in table I. Prices, average weights and feed 
costs differ according to sex. Thus, economic margins were computed for each sex and average values were derived by weighting values for each sex by the relative frequency of males (or females) sold. The prices used were those indicated by Belard et al (1992). Relative economic margins are basically dependent on assumptions about feeding diets. Direct effects on preweaning growth are less profitable than maternal effects, because an additional kilogram of weaning weight due to direct effects was obtained from concentrate, which is an expensive feed source compared to milk. Growth from maternal milk is more valuable because dams partly produce milk from forage and pasture, ie a cheap feed source. Likewise, economic margin per additional kilogram of final weight was higher than before weaning, because cheaper feed sources, such as maize silage, are used. Appendix II presents a full description of the calculation.

Table I. Figures used for derivation of economic margins.

\begin{tabular}{lcc}
\hline Criterion & Male & Female \\
\hline Average live weight (kg) & & \\
$\quad$ At 210 d & 300 & 275 \\
$\quad$ At 500 d & 600 & 475 \\
Sex ratio for calves sold (\%) & & \\
$\quad$ At 210 d & 73 & 27 \\
At 500 d & 55 & 45 \\
Price per kg sold in 1991 (FF) & & \\
$\quad$ At 210 d & 17.2 & 15.7 \\
$\quad$ At 500 d & 15.5 & 17.5 \\
Marginal feed cost per kg (FF) & & \\
$\quad$ At 210 d & 3.0 & 3.0 \\
$\quad$ Maternal effect & 6.5 & 6.5 \\
$\quad$ Direct effect & & \\
At 500 d & & \\
$\quad$ Direct effect & 6.1 & 3.5 \\
\hline
\end{tabular}

FF: French francs.

The following breeding objectives (in $\mathrm{FF}$ ) were derived, with As and Ms in kilograms:

- the suckler objective: $H \mathrm{~s}=10 \mathrm{~A} 210+14 \mathrm{M} 210$

- the suckler-fattening objective: $H \mathrm{f}=-5 \mathrm{~A} 210-1 \mathrm{M} 210+12 \mathrm{~A} 500$

- the global objective: $H \mathrm{~g}=5 \mathrm{~A} 210+9 \mathrm{M} 210+4 \mathrm{~A} 500$

In the past, some theoretical studies (Hanrahan, 1976; Van Vleck et al, 1977; Hanset, 1981; Azzam and Nielsen, 1987) presented breeding objectives with the same economic weight for direct and maternal effects, without any justification of this choice. As far as we know, only Ponzoni and Newman (1989) separated direct and maternal effects in the breeding objective for Australian beef cattle. However, they assumed that $1 \mathrm{~kg}$ of W210 due to direct effects has the same cost as $1 \mathrm{~kg}$ of W210 due to maternal effects. The only difference they considered was the number of expressions of direct effects compared to the number of expressions of maternal 
effects within a 20-year period and for a $5 \%$ discount rate. However, the ratio of numbers of direct expressions to maternal ones depends very much on the discount rate and, to a lesser extent, on the assumptions concerning the population structure. For a zero discount rate and overlapping generations, this ratio is asymptotically equal to 1 for any population structure without a closed nucleus. Since our purpose was to calculate asymptotic genetic gains (Phocas et al, 1995), we found that it was more consistent to derive the breeding objective from the asymptotic ratio of expressions, $i e$ for the same number of direct and maternal expressions.

\section{Description of the breeding scheme}

The Limousin breed is the second French beef cattle breed with about 600000 cows; $10 \%$ of these cows are registered and recorded, and they constitute the selection nucleus. The AI rate is about $10 \%$ in the nucleus and about $20 \%$ in the whole Limousin population. The current selection program has been implemented since 1980 and combines both AI and NS bull selection. Selection is performed in a sequential way with independent culling levels on individual and progeny performance. Complexity is induced by the existence of 2 paths for AI bull selection. Each of these paths implies an individual station performance test and a progeny performance test (fig 1). In the first path, AI bulls are selected after a 'long performance test' and a progeny test in station (Ménissier, 1988). Bulls are measured over 6 months on individual growth, muscular and skeletal development and feed intake; the progeny test concerns beef traits (on young bulls' production) and maternal performance (on primiparous daugthers). More recently, some AI bulls have completed tests from a cheaper selection program, which reduced costs for individual performance testing (a 4-month period without feed intake recording) and for progeny testing (on-farm, limited to direct effects on preweaning performance). This last test is performed by using reference AI bulls (the so-called 'connection sires') that provide statistical links for breeding value estimation (Foulley and Sapa, 1982). Exchange between both selection paths is currenty developing.

Alternative breeding schemes might be envisaged to simplify the breeding scheme and to reduce costs. For that purpose, a simplified scheme was constructed, considering only 'short performance test' in station and progeny performance test on-farm (fig 2). The on-farm progeny index was modified to take maternal performance into account: a combined index of the average W210 of 30 sons and the average W120 of calves of bulls' daughters was built. It was assumed that heritability of maternal effects is lower on-farm $\left(h^{2}=0.16\right)$ than in station $\left(h^{2}=0.26\right)$, since environmental effects are better controlled in station.

\section{Derivation and optimization of selection differentials}

\section{Optimization of selection differentials for the current breeding scheme}

The AI bull selection is optimized by considering each section of the current breeding scheme as a variate within an overall multivariate selection. This leads to the use of a method previously developed by Ducrocq and Colleau (1989) for finding optimum selection thresholds in multistage selection, assuming a multivariate 


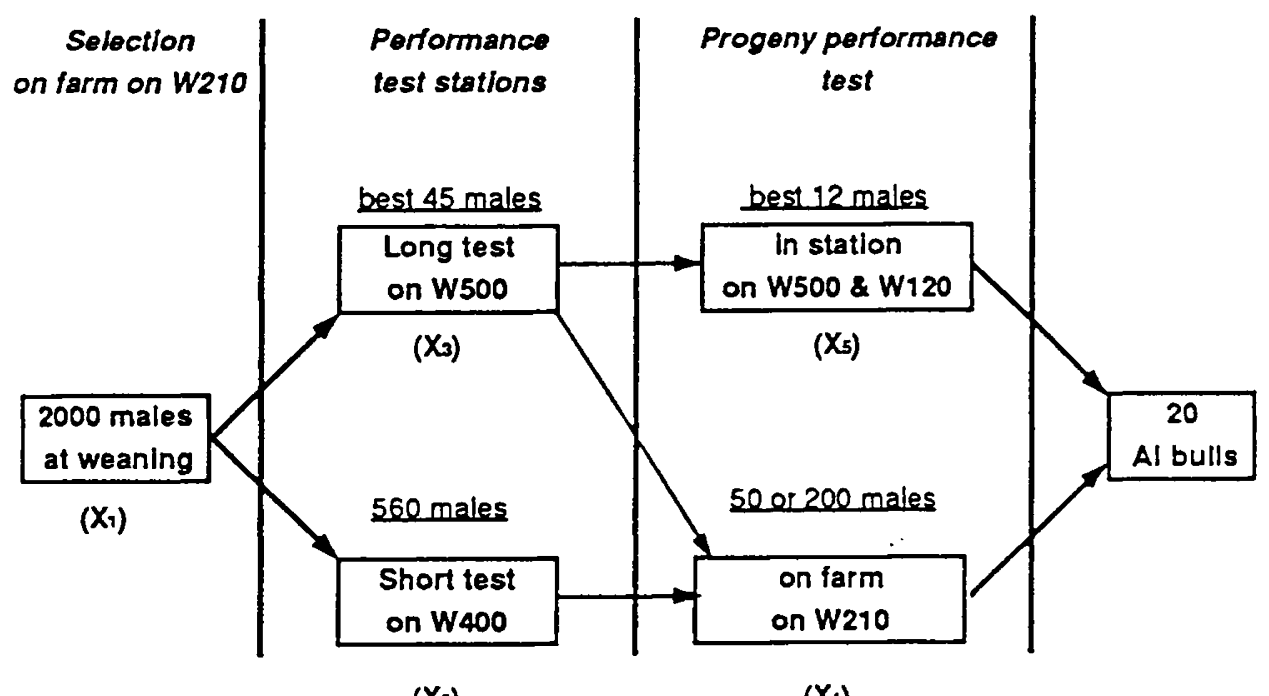

( $\left.X_{2}\right)$

$\left(x_{4}\right)$

Fig 1. Current selection scheme of AI bulls.

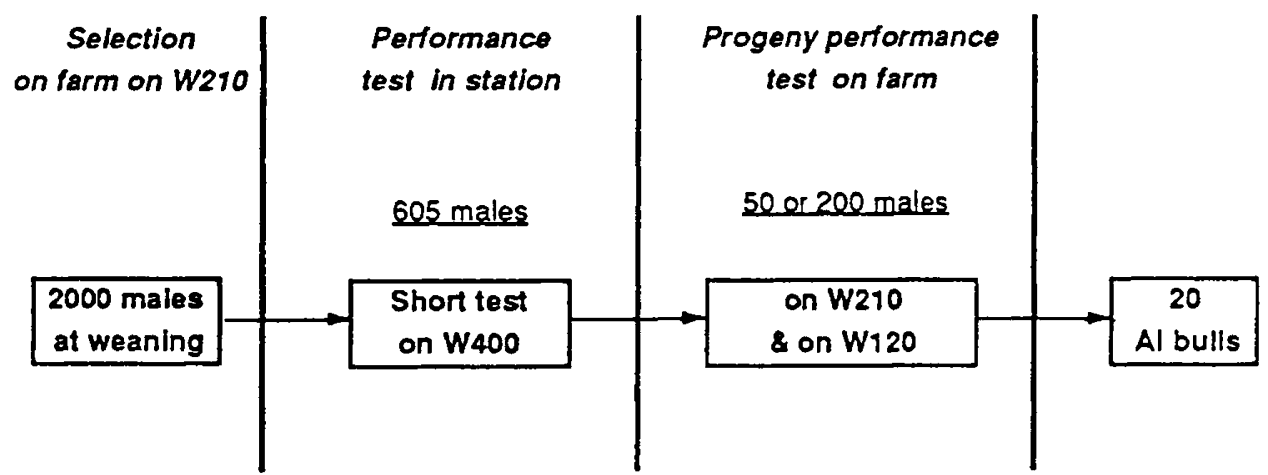

Fig 2. Simplified selection scheme of AI bulls.

normal distribution and treating candidates for selection as independent observations. Optimum selection thresholds are thresholds which maximize the selection response.

Let us define the following variables:

$X_{1}$, the $210 \mathrm{~d}$ weight $(\mathrm{W} 210)$

$X_{2}$, the $400 \mathrm{~d}$ weight (W400)

$X_{3}$, the $500 \mathrm{~d}$ weight (W500)

$X_{4}$, the average $\mathrm{W} 210$ of 30 sons

$X_{5}$, the index $\left(I_{s}\right)$ combining the average W500 of 30 sons and the average W120 (120 d weight) of 20 daughter's calves ( 1 calf per daughter). 
$X_{1}, X_{2}, X_{3}, X_{4}, X_{5}$, the breeding value $H$ and components of $H$ are random variables with a multivariate normal distribution. The function to maximize is the average breeding value $(H)$ of the bulls finally selected for use in AI, whatever the origin:

$$
\begin{aligned}
& H=P\left(X_{1}>a_{1}, X_{3}>a_{3}, X_{5}>a_{5}\right) E\left(H \mid X_{1}>a_{1}, X_{3}>a_{3}, X_{5}>a_{5}\right) \\
& +P\left(X_{1}>a_{1}, b_{3}<X_{3}<a_{3}, X_{4}>a_{4}\right) E\left(H \mid X_{1}>a_{1}, b_{3}<X_{3}<a_{3}, X_{4}>a_{4}\right) \\
& +P\left(b_{1}<X_{1}<a_{1}, X_{2}>a_{2}, X_{4}>a_{4}\right) E\left(H \mid b_{1}<X_{1}<a_{1}, X_{2}>a_{2}, X_{4}>a_{4}\right)
\end{aligned}
$$

where the $a_{i}$ s and the $b_{i}$ s are the selection thresholds on the $X_{i}$ variates.

To illustrate the reasoning, let us consider the category of on-farm progeny tested bulls selected from the 'short performance test'. These bulls are not the best ones at weaning; their weight W210 is lower than a first threshold $a_{1}$ but larger than a second threshold $b_{1}\left(b_{1}<X_{1}<a_{1}\right)$. A second threshold occurs on W400; the males selected for on-farm progeny test are above a threshold $a_{2}\left(X_{2}>a_{2}\right)$. A final threshold $a_{4}$ has to be added as the result of on-farm progeny test selection $\left(X_{4}>a_{4}\right)$.

Thresholds $a_{1}$ and $b_{1}$ for W210 are obtained directly (fig 1). The other thresholds are computed after optimizing the above non-linear function, with constraints on the proportion of males selected for station progeny test (12:2000), the proportion selected for on-farm progeny test (current 50:2 000 or envisaged 200:2 000) and the final proportion of AI bulls selected (20:2 000). A Newton-Raphson algorithm is set up taking these constraints into account through Lagrange multipliers.

\section{Derivation of selection differentials for the simplified breeding scheme}

For the simplified scheme, each threshold was obtained directly, since the number of candidates for each test is fixed (fig 2). Thus, there is no optimization.

\section{Genetic parameters}

\section{Estimation}

The genetic parameters used in the present study (table II) for direct and maternal effects on weight at 120 and 210 d were estimated by Shi et al (1993) for the French Limousin breed. The other parameters are literature averages (Renand et al, 1992). Correlations between selection goals and selection indices are also presented in table III. The procedure proposed by Foulley and Ollivier (1986) was used to test the consistency of phenotypic and genetic covariance matrices.

\section{Uncertainty}

As underlined by Meyer (1992), sampling covariances of estimates of variance components including maternal effects are very high even for designs specifically dedicated to the estimation of maternal effects. Thus, the accuracy of predicted responses (especially indirect responses for maternal effects) should be assessed from sampling covariances of dispersion parameters. However, these sampling covariances 
Table II. Heritabilities and standard deviations ${ }^{\mathrm{a}}$.

\begin{tabular}{lcc}
\hline Trait & Heritability & Standard deviation $(\mathrm{kg})$ \\
\hline A500 & 0.40 & 29.1 \\
A210 & 0.26 & 11.6 \\
M210 & 0.14 & 8.2 \\
W210 & 0.26 & 22.8 \\
W400 & 0.30 & 40.0 \\
W500 & 0.40 & 46.0 \\
\hline
\end{tabular}

a Appendix I gives the meaning of the abbreviations used to designate variables.

Table III. Correlations between breeding objectives, their components, performance and progeny-test averages ${ }^{\mathrm{a}}$.

\begin{tabular}{lccccccccc}
\hline & $A 500$ & $A 210$ & M210 & W210 & $W 400$ & $W 500$ & $\mathrm{I}_{s}$ & $\mathrm{I}_{f 1}$ & $\mathrm{I}_{f 2}$ \\
\hline $\mathrm{Hg}$ & 0.89 & 0.80 & 0.22 & 0.45 & 0.45 & 0.56 & 0.85 & 0.66 & 0.75 \\
$\mathrm{Hs}$ & 0.50 & 0.62 & 0.61 & 0.42 & 0.28 & 0.31 & 0.77 & 0.51 & 0.81 \\
$\mathrm{Hf}$ & 0.99 & 0.73 & -0.20 & 0.33 & 0.48 & 0.63 & 0.87 & 0.60 & 0.54 \\
$\mathrm{~A} 500$ & 1 & 0.80 & -0.20 & 0.37 & 0.49 & 0.63 & 0.82 & 0.66 & 0.57 \\
$\mathrm{~A} 210$ & & 1 & -0.24 & 0.46 & 0.45 & 0.51 & 0.70 & 0.82 & 0.71 \\
M210 & & & 1 & 0.06 & -0.11 & -0.12 & 0.07 & -0.20 & 0.25 \\
W210 & & & & 1 & 0.75 & 0.70 & 0.37 & 0.38 & 0.41 \\
W400 & & & & & 1 & 0.80 & 0.41 & 0.37 & 0.32 \\
W500 & & & & & & 1 & 0.52 & 0.42 & 0.36 \\
\hline
\end{tabular}

a Appendix I gives the meaning of abbreviations used to designate variables.

are seldom calculated because of exceedingly high computing costs. Hence, the sampling variance-covariance matrix of restricted maximum likelihood (REML) estimates for preweaning genetic parameters is derived from a theoretical layout, roughly mimicking the real structure of the data. Postweaning parameters are well known and, consequently, are not considered in this study.

The same $p$ unrelated bulls are sires (S) of a first progeny generation and maternal grandsires (MGS) of a second progeny generation. These bulls are also unrelated to the $p$ maternal grandsires of the first generation and the $p$ sires of the second generation. We additionally assume that a constant number $(d)$ of calves is obtained from each pair S-MGS and that these $d$ offspring are born from unrelated dams. The statistical model used to analyse these data is a bivariate (W120 and W210) S-MGS model. For a $c$-trait model and the above layout, the sampling variance-covariance matrix of REML estimators is derived from matrices of maximal size $4 c \times 4 c$ (Appendix III). The number $d$ of offspring per pair S-MGS is equal to 1 in our numerical application. Three numbers of bulls are considered: $p=20,45$ or 125; the value 45 leads to coefficients of variation on additive variances around $20 \%$, which is a frequent value seen in literature for direct heritabilities. 
$\boldsymbol{\theta}$, the vector of direct and maternal dispersion parameters, is easily obtained from $\boldsymbol{\theta}^{*}$, the vector of dispersion parameters of the S-MGS model: $\boldsymbol{\theta}^{*}=\mathbf{M} \boldsymbol{\theta}$ where $\mathbf{M}$ is a constant matrix. Then $\operatorname{Var}(\boldsymbol{\theta})=\mathbf{M}^{-1} \operatorname{Var}\left(\boldsymbol{\theta}^{*}\right) \mathbf{M}^{-1^{\prime}}$, where $\mathbf{M}^{-1^{\prime}}$ is the transposed matrix of $\mathbf{M}^{-1}$.

These sampling variance-covariance matrices are then used to compute the approximate variance of selection response $H . H$ is approximated by the firstorder term of a Taylor expansion. As underlined by Harris (1964), this is a common method for deriving variance of complex functions.

$$
H(\boldsymbol{\theta}) \approx H\left(\boldsymbol{\theta}_{0}\right)+\mathbf{G}\left(\boldsymbol{\theta}_{0}\right)^{\prime}\left[\boldsymbol{\theta}-\boldsymbol{\theta}_{0}\right]
$$

where $\theta_{0}$ is the vector of unbiased point estimates $\left(E(\boldsymbol{\theta})=\boldsymbol{\theta}_{0}\right)$

$$
\begin{gathered}
\text { and } \mathbf{G}\left(\boldsymbol{\theta}_{0}\right)=\left(\frac{\partial H(\boldsymbol{\theta})}{\partial \boldsymbol{\theta}}\right)_{\boldsymbol{\theta}=\boldsymbol{\theta}_{0}} \\
\operatorname{Var}[H(\boldsymbol{\theta})] \approx \mathbf{G}\left(\boldsymbol{\theta}_{0}\right)^{\prime}\left[\operatorname{Var}\left(\boldsymbol{\theta}-\boldsymbol{\theta}_{0}\right)\right] \mathbf{G}\left(\boldsymbol{\theta}_{0}\right)
\end{gathered}
$$

Obtaining the first derivatives is tedious. Thus, they are computed by finite differences of $H$ :

$$
G_{i}\left(\boldsymbol{\theta}_{0}\right)=\frac{1}{e}\left[H\left(\boldsymbol{\theta}_{0}+0.5 \varepsilon_{i}\right)-H\left(\boldsymbol{\theta}_{0}-0.5 \varepsilon_{i}\right)\right]
$$

where $G_{i}\left(\boldsymbol{\theta}_{0}\right)$ is the $i$ th term of $\mathbf{G}\left(\boldsymbol{\theta}_{0}\right)$

and $\varepsilon_{i}$ is a vector of zeros except the $i$ th term which is equal to $e$. For $e$ between $10^{-2}$ and $10^{-5} \mathrm{~kg}^{2}$, the results are very stable: the first 4 decimals of the sampling standard deviation of the standardized selection differential are always the same.

\section{RESULTS AND DISCUSSION}

\section{Efficiency of the current selection scheme}

\section{Optimum choice of AI bulls according to their origin}

The optimum number of AI bulls to select after on-farm progeny test is almost independent of the objective and of the farm progeny test capacity (either 50 or 200 bulls). It varies from 13 to 14 males out of the 20 AI bulls selected (table IV). The majority of AI bulls are selected after the on-farm progeny test due to a larger progeny test capacity compared to the station progeny test capacity (12 bulls). However, the probability of selection is higher for a station progeny tested bull: more than $50 \%$ ( 6 or 7 bulls out of 12 ) versus less than $30 \%$ (13 or 14 bulls out of 50 or 200) for on-farm progeny tested bulls. If the objective includes final weight, the station progeny tested bulls are favored because the corresponding direct effects are better assessed in the 'long performance test'. If the objective concerns weaning weight, they are favored because they are the best at weaning (fig 1) and also because the maternal performance of their daughters is assessed. 
Table IV. Origin of the 20 selected AI bulls according to breeding objective and farm progeny test capacity.

\begin{tabular}{lcccc}
\hline Breeding objective & $\begin{array}{c}\text { No of on-farm } \\
\text { progeny tested bulls }\end{array}$ & \multicolumn{3}{c}{ No of bulls selected } \\
\cline { 3 - 5 } & & $\begin{array}{c}\text { Station progeny } \\
\text { test and long } \\
\text { performance test }\end{array}$ & $\begin{array}{c}\text { On-farm progeny test } \\
\text { performance } \\
\text { test }\end{array}$ & $\begin{array}{c}\text { Short } \\
\text { performance } \\
\text { test }\end{array}$ \\
\hline Global & & & 6 & 7 \\
$(H \mathrm{~g})$ & 50 & 7 & 3 & 11 \\
Suckler & 200 & 6 & 9 & 5 \\
$(H \mathrm{~s})$ & 50 & 6 & 3 & 11 \\
Suckler-fattener & 200 & 6 & 3 & 10 \\
$(H \mathrm{f})$ & 50 & 7 & 2 & 12 \\
\hline
\end{tabular}

By assumption, all the AI bulls selected after station progeny test were first evaluated in a 'long performance test'. Conversely, the location of performance test of the 13 or 14 bulls selected after on-farm progeny test depends very much on breeding objective and on progeny test capacity (table IV). At low progeny test capacity, the numbers of these AI bulls first selected in the 'long performance test' are 9, 3 and 6, respectively for $H \mathrm{~s}, H \mathrm{f}$ and $H \mathrm{~g}$; at higher progeny test capacity, the corresponding numbers are 3,2 and 3 . Therefore, different selection policies should be employed for bulls used in suckler herds or suckler-fattening herds.

\section{Selection responses}

The maximal selection responses for each of the 3 objectives studied are presented in table V. In each case, the selection response in $\mathrm{Hg}$ is given in order to evaluate the loss of efficiency occurring when the objective considered $(H \mathrm{~s}, H \mathrm{f})$ does not correspond to the true economic objective for the breed $(\mathrm{Hg})$.

At low progeny test capacity on-farm, selection responses range from $1.38 \sigma_{H \mathrm{~s}}$ when selecting on $H \mathrm{~s}$ to $1.72 \sigma_{\mathrm{Hg}}$ when selecting on $H \mathrm{~g}$. The scheme appears to be more efficient for suckler-fattening herds than for suckler herds. However, the highest efficiency occurs when selecting for $\mathrm{Hg}$. Whatever the objective, an improvement of direct effects is expected, but the genetic trend of maternal effects on W210 is negative (table VI). This stems basically from the genetic antagonism between direct and maternal effects $(r \mathrm{~g}=-0.24)$.

Selection responses are 3-6\% larger at high versus low farm test capacity. This increase is more significant for $H \mathrm{~g}$ than for $\mathrm{Hs}$ or $H \mathrm{f}$, due to the higher accuracy of on-farm progeny selection index $I_{\mathrm{f} 1}$ (table III) for predicting $H \mathrm{~g}$ than for predicting $H \mathrm{f}$ or $H$ s. Moreover, the impact of a higher farm progeny test capacity is less significant for $H \mathrm{~s}$ than for $\mathrm{Hg}$ or $H \mathrm{f}$, since farm progeny tested bulls are not evaluated on maternal performance. 
Table V. Expected selection responses (in $\sigma_{\mathbf{H}}$ units).

\begin{tabular}{lccc}
\hline Breeding objective $\mathrm{H} i$ & $\begin{array}{c}\text { No of farm progeny } \\
\text { tested bulls }\end{array}$ & Response in $\mathrm{H} i$ & Response in $\mathrm{H} g$ \\
\hline Current scheme & & & \\
Hg: global & 50 & 1.75 & 1.75 \\
& 200 & 1.87 & 1.87 \\
Hs: suckler & 50 & 1.38 & 1.69 \\
& 200 & 1.42 & 1.85 \\
Hf: suckler-fattener & 50 & 1.72 & 1.73 \\
& 200 & 1.77 & 1.85 \\
Simplified scheme & & & \\
Hg: global & 50 & 1.70 & 1.70 \\
& 200 & 1.97 & 1.97 \\
Hs: suckler & 50 & 1.41 & 1.69 \\
& 200 & 1.87 & 1.94 \\
Hf: suckler-fattener & 50 & 1.52 & 1.65 \\
& 200 & 1.57 & 1.87 \\
\hline
\end{tabular}

Table VI. Selection responses (in $\sigma_{\mathrm{G}}$ units) in the basic traits: expected values and standard deviation for a medium uncertainty ${ }^{\mathrm{a}}$ in preweaning genetic parameters (in brackets).

\begin{tabular}{lcccc}
\hline Breeding objective & $\begin{array}{c}\text { No of farm progeny } \\
\text { tested bulls }\end{array}$ & $\begin{array}{c}\text { Weaning weight } \\
\text { (direct) }\end{array}$ & $\begin{array}{c}\text { Weaning weight Final weight } \\
\text { (maternal) }\end{array}$ & $\begin{array}{c}\text { (direct) } \\
\text { Current scheme }\end{array}$ \\
Hg: global & 50 & $1.85(0.22)$ & $-0.26(0.37)$ & $1.75(0.02)$ \\
& 200 & $2.06(0.25)$ & $-0.35(0.42)$ & $1.87(0.03)$ \\
Hs: suckler & 50 & $1.80(0.23)$ & $-0.11(0.34)$ & $1.58(0.04)$ \\
& 200 & $2.03(0.25)$ & $-0.29(0.40)$ & $1.80(0.04)$ \\
Hf: suckler-fattener & 50 & $1.83(0.22)$ & $-0.39(0.40)$ & $1.81(0.04)$ \\
& 200 & $2.05(0.25)$ & $-0.42(0.43)$ & $1.89(0.03)$ \\
Simplified scheme & & & & \\
Hg: global & 50 & $1.66(0.20)$ & $0.03(0.30)$ & $1.58(0.06)$ \\
& 200 & $1.89(0.27)$ & $0.34(0.35)$ & $1.66(0.11)$ \\
Hs: suckler & 50 & $1.59(0.22)$ & $0.14(0.27)$ & $1.53(0.09)$ \\
& 200 & $1.76(0.31)$ & $0.54(0.32)$ & $1.55(0.17)$ \\
Hf: suckler-fattener & 50 & $1.70(0.20)$ & $-0.15(0.36)$ & $1.61(0.05)$ \\
& 200 & $1.96(0.26)$ & $0.01(0.42)$ & $1.70(0.09)$ \\
\hline
\end{tabular}

a See table VII for $p=45$ bulls.

Whatever the objective, selection response for $\mathrm{Hg}$ has been derived. From this calculation (table V), it can be concluded that selection response is robust to errors in determining breeding objectives. The loss of economic response for the whole 
Limousin population (evaluated on $\mathrm{Hg}$ ) would be negligible whatever the breeding objective: -3 and $-1 \%$ when breeding objectives are $H \mathrm{~s}$ and $H \mathrm{f}$, respectively, at low progeny test capacity; $-1 \%$ whatever the objective, at higher progeny test capacity.

\section{Change in efficiency in a simplified selection scheme}

The evolution of efficiency depends very much on the objective and on-farm progeny test capacity (table V). At low capacity of on-farm progeny test, the differences between the 2 schemes in selection responses range from -12 to $+2 \%$. The lowest value is for the fattener objective $(H \mathrm{f})$, the highest for the calf producer objective $(\mathrm{Hs})$. If selection concerns final weight, simplification of the scheme leads to a loss of efficiency since final weight is better assessed in the 'long performance test'. If selection concerns direct and maternal effects at weaning, it leads to a gain of efficiency since all bulls progeny tested are evaluated on W210 of their sons and on the maternal performance of their daughters. At high on-farm progeny test capacity, a large gain of efficiency occurs when selecting on $\mathrm{Hs}(32 \%)$ or $\mathrm{Hg}(5 \%)$ with the simplified scheme; the loss of efficiency when selecting on $H \mathrm{f}$ is still $11 \%$.

In the simplified scheme, positive maternal response is expected for $H \mathrm{~s}$ and $\mathrm{Hg}$ at low progeny test capacity, whatever the breeding objective at higher progeny test capacity.

\section{Accuracy of predicted selection response}

Some idea of the variance of predicted response is required to plan and justify a breeding progam. Assuming that genetic parameters are really known, variability of selection response is due to genetic sampling and drift. Woolliams and Meuwissen (1993) show how sampling variance and expectation of selection response can be weighted to choose between alternative breeding schemes using utility theory. In our study, another aspect is considered, the variance of the predicted response due to inaccurate estimates of genetic parameters. The purpose is to clarify the situation for maternal genetic response.

\section{Sampling variances and correlations}

Three different levels of uncertainty in genetic parameters of W120 and W210 are studied, depending on the number of bulls evaluated as sires and maternal grandsires: 20,45 or 125 bulls. The sampling variances and the sampling correlations between estimates of genetic components are presented in tables VII and VIII respectively. It should be noticed that the magnitude of sampling variances and correlations is nearly independent of the trait considered (W120 or W210).

For the case of 20 bulls, uncertainty (expressed as the ratio of the sampling standard deviation to the absolute value of the estimate of genetic component, called coefficient of variation) in direct (co)variances is around $40 \%$ whereas uncertainty in maternal (co)variances is around $80 \%$. Uncertainties in direct and maternal (co)variances decrease to 20 and $30 \%$ respectively in the case of 45 bulls and to 10 and $14 \%$ in the case of 125 bulls. However the largest uncertainties concern the estimates of covariances between direct and maternal effects, around $200 \%$ for the 
Table VII. Coefficients of variation (in \%) of preweaning parameters ${ }^{\mathrm{a}}$.

\begin{tabular}{rcccccccccc}
\hline $\mathrm{p}$ & $\sigma_{A_{1}}^{2}$ & $\sigma_{M_{1}}^{2}$ & $\sigma_{A_{1} M_{1}}$ & $\sigma_{A_{1} A_{2}}$ & $\sigma_{M_{1} M_{2}}$ & $\sigma_{A_{1} M_{2}}$ & $\sigma_{M_{1} A_{2}}$ & $\sigma_{A_{2}}^{2}$ & $\sigma_{M_{2}}^{2}$ & $\sigma_{A_{2} M_{2}}$ \\
\hline 20 & 39 & 86 & 190 & 41 & 81 & 216 & 246 & 40 & 79 & 198 \\
45 & 20 & 32 & 88 & 21 & 33 & 99 & 114 & 20 & 34 & 91 \\
125 & 10 & 14 & 41 & 11 & 14 & 46 & 53 & 10 & 15 & 42 \\
\hline
\end{tabular}

${ }^{a} p$ is the number of bulls evaluated as sires and maternal grandsires in order to estimate the genetic parameters (A: direct; M: maternal); subscript 1 concerns parameters for weight at $120 \mathrm{~d}$; subscript 2 concerns parameters for weight at $210 \mathrm{~d}$.

Table VIII. Sampling correlations between estimates of preweaning parameters for a medium uncertainty in sampling variances ${ }^{\mathrm{a}}$.

\begin{tabular}{lcccccccccc}
\hline & $\sigma_{A_{1}}^{2}$ & $\sigma_{M_{1}}^{2}$ & $\sigma_{A_{1} M_{1}}$ & $\sigma_{A_{1} A_{2}}$ & $\sigma_{M_{1} M_{2}}$ & $\sigma_{A_{1} M_{2}}$ & $\sigma_{M_{1} A_{2}}$ & $\sigma_{A_{2}}^{2}$ & $\sigma_{M_{2}}^{2}$ & $\sigma_{A_{2} M_{2}}$ \\
\hline$\sigma_{A_{1}}^{2}$ & 1 & 0.07 & -0.31 & 0.94 & 0.06 & -0.29 & -0.29 & 0.80 & 0.04 & -0.26 \\
$\sigma_{M_{1}}^{2}$ & 1 & -0.54 & 0.08 & 0.96 & -0.53 & -0.47 & 0.08 & 0.83 & -0.46 \\
$\sigma_{A_{1} M_{1}}$ & & 1 & -0.27 & -0.54 & 0.92 & 0.89 & -0.21 & -0.48 & 0.81 \\
$\sigma_{A_{1} A_{2}}$ & & & & 1 & 0.07 & -0.30 & -0.29 & 0.94 & 0.06 & -0.31 \\
$\sigma_{M_{1} M_{2}}$ & & & & 1 & 0.56 & -0.54 & 0.07 & 0.95 & -0.55 \\
$\sigma_{A_{1} M_{2}}$ & & & & & 1 & 0.84 & -0.28 & -0.54 & 0.89 \\
$\sigma_{M_{1} A_{2}}$ & & & & & & 1 & -0.25 & -0.56 & 0.92 \\
$\sigma_{A_{2}}^{2}$ & & & & & & & 1 & 0.07 & -0.33 \\
$\sigma_{M_{2}}^{2}$ & & & & & & & & 1 & -0.61 \\
$\sigma_{A_{2} M_{2}}^{2}$ & & & & & & & & & 1 \\
\hline
\end{tabular}

${ }^{\text {a }} p=45$ bulls evaluated as sires and maternal grandsires in order to estimate the genetic parameters (A: direct; M: maternal); subscript 1 concerns parameters for weight at $120 \mathrm{~d}$; subscript 2 concerns parameters for weight at $210 \mathrm{~d}$.

case of 20 bulls, $100 \%$ for the case of 45 bulls and $50 \%$ for the case of 125 bulls. Sampling correlations do not differ very much according to the number of bulls. Whatever the number of bulls, the highest sampling correlations (in absolute values) are obtained between genetic components of the same kind ( 2 additive (co)variances, or 2 maternal (co)variances, or 2 direct-maternal covariances).

Within trait, our results lead to the same conclusions as those obtained from different structures of data and different genetic parameters by Meyer (1992). Sampling correlations between additive or maternal genetic variance and the directmaternal covariances are medium (0.3-0.6). Sampling correlation between additive variance and maternal variance is smaller than previous correlations. In our study, this correlation is around 0.07; in Meyer's work the value ranged from 0.04 to 0.48 , depending on the structure of data. 


\section{Standard deviation of predicted selection responses}

Standard deviations of predicted selection responses are presented in table IX for the 3 sampling variance-covariance matrices defined above. These standard deviations are similar whatever the structure of the selection scheme (current or simplified), but depend very much on the breeding objective. They are high for $H \mathrm{~s}$ and almost nonexistent for $H \mathrm{f}$. This is easily explained by the fact that uncertainty was only considered for preweaning parameters. Sampling standard deviations of differentials for $H \mathrm{~s}$ are in the range of uncertainty in maternal variance of W210. Standard deviations for selection differentials in $\mathrm{Hg}$ are in the range of uncertainties in direct genetic variances. For the current scheme, these standard deviations are nearly independent of the progeny test capacity. For the simplified scheme, standard deviations increase when progeny test capacity increases. More males are evaluated on maternal performance and thus the uncertainty in preweaning parameters has a larger impact. The same comments can be made for the standard deviations of the objective components (table VI). Standard deviations of direct and maternal responses in W210 are in the range of the respective uncertainties in direct and maternal variances for W210. If $95 \%$ confidence intervals are considered, the following remark must be made. For the current scheme, the predicted maternal response could be positive but for the simplified scheme it could be negative.

Table IX. Standard deviations of standardized selection responses.

\begin{tabular}{lcccc}
\hline Breeding objective & $\begin{array}{c}\text { No of on-farm } \\
\text { progeny tested } \\
\text { (bulls) }\end{array}$ & $\begin{array}{c}\text { Standard } \\
\text { deviation for } \\
\mathrm{p}=20^{\mathrm{a}}\end{array}$ & $\begin{array}{c}\text { Standard } \\
\text { deviation for } \\
\mathrm{p}=45^{\mathrm{a}}\end{array}$ & $\begin{array}{c}\text { Standard } \\
\text { deviation for } \\
\mathrm{p}=125^{\mathrm{a}}\end{array}$ \\
\hline $\begin{array}{l}\text { Current scheme } \\
\text { Hg: global }\end{array}$ & 50 & 0.38 & 0.18 & 0.8 \\
Hs: suckler & 200 & 0.42 & 0.20 & 0.9 \\
& 50 & 0.66 & 0.31 & 0.15 \\
Hf: suckler-fattener & 200 & 0.73 & 0.34 & 0.16 \\
& 50 & 0.3 & 0.2 & 0.0 \\
Simplified scheme & 200 & 0.2 & 0.1 & 0.0 \\
Hg: global & & & & \\
& 50 & 0.40 & 0.19 & 0.9 \\
Hs: suckler & 200 & 0.52 & 0.24 & 0.12 \\
& 50 & 0.61 & 0.28 & 0.13 \\
Hf: suckler-fattener & 200 & 0.73 & 0.34 & 0.16 \\
& 50 & 0.7 & 0.3 & 0.2 \\
\hline
\end{tabular}

${ }^{\mathrm{a}} p$ is the number of bulls evaluated as sire and maternal grandsire.

In animal breeding, only Tallis (1960), Harris (1964) and Sales and Hill (1976a, b) seem to have considered the influence of uncertain statistical dispersion parameters on the variance of predicted genetic gains. They found high variances of predicted efficiency of a selection index. Our study for a more complex selection suggests that 
this aspect should not be overlooked when setting up breeding plans and evaluating genetic responses.

\section{Analysis of sensitivity to direct-maternal correlations}

Alternative analyses were carried out according to different values of directmaternal correlation $\left(r_{\mathrm{AM}}\right): r_{\mathrm{AM}}=0$ and $r_{\mathrm{AM}}=-0.6$. Indeed, very variable values are observed in the literature. Table $\mathrm{X}$ presents corresponding selection responses for the 3 objectives and for the 2 breeding schemes considered in this study. Of course, all the selection responses are lower when $r_{\mathrm{AM}}$ is more negative. Hovewer only maternal response and response in $H \mathrm{~s}$ are very sensitive to $r_{\mathrm{AM}}$ value. Whatever the direct-maternal correlation (between 0 and -0.6), the choice of the most efficient breeding scheme is unchanged. The simplified scheme is really interesting (compared to the current scheme) for high progeny test capacity and objective $H \mathrm{~s}$; the gain in efficiency in $H \mathrm{~s}$ is higher as direct and maternal effects are opposed $(42 \%$ for $r_{\mathrm{AM}}=-0.6$ instead of $26 \%$ for $r_{\mathrm{AM}}=0$ ), because, in the simplified scheme, a larger number of bulls are evaluated on maternal performance. For the same reason, the loss in efficiency in $H \mathrm{f}$ due to simplification of the breeding scheme is higher as $r_{\mathrm{AM}}$ becomes negative. The same comment can be made for $\mathrm{Hg}$ at low progeny test capacity. At higher progeny test capacity, a small loss in efficiency in $\mathrm{Hg}(-3 \%)$ is observed for very negative direct-maternal correlation $\left(r_{\mathrm{AM}}=-0.6\right)$, but otherwise a gain in efficiency in $\mathrm{Hg}$ is obtained by simplifying the breeding scheme.

Table X. Expected selection responses (in $\sigma_{\mathrm{H}}$ units) according to the value of genetic direct-maternal correlation $\left(r_{\mathrm{AM}}\right)$.

\begin{tabular}{|c|c|c|c|c|c|c|c|c|c|}
\hline \multirow[t]{2}{*}{ Breeding objective } & \multirow[t]{2}{*}{$\mathrm{r}_{A M}$} & \multicolumn{4}{|c|}{$\begin{array}{c}\text { Responses at low progeny } \\
\text { test capacity }\end{array}$} & \multicolumn{4}{|c|}{$\begin{array}{c}\text { Responses at high progeny } \\
\text { test capacity }\end{array}$} \\
\hline & & $H$ & A210 & M210 & $A 500$ & $H$ & A210 & M210 & $A 500$ \\
\hline $\begin{array}{l}\text { Current scheme } \\
H \text { g: global }\end{array}$ & $\begin{array}{c}0 \\
-0.6\end{array}$ & $\begin{array}{l}1.82 \\
1.69\end{array}$ & $\begin{array}{l}1.89 \\
1.81\end{array}$ & $\begin{array}{r}0.23 \\
-1.00\end{array}$ & $\begin{array}{l}1.75 \\
1.77\end{array}$ & $\begin{array}{l}1.93 \\
1.78\end{array}$ & $\begin{array}{l}2.08 \\
2.04\end{array}$ & $\begin{array}{r}0.16 \\
-1.13\end{array}$ & $\begin{array}{l}1.88 \\
1.85\end{array}$ \\
\hline$H$ s: suckler & $\begin{array}{c}0 \\
-0.6\end{array}$ & $\begin{array}{l}1.56 \\
1.03\end{array}$ & $\begin{array}{l}1.86 \\
1.71\end{array}$ & $\begin{array}{r}0.34 \\
-0.81\end{array}$ & $\begin{array}{l}1.63 \\
1.53\end{array}$ & $\begin{array}{l}1.61 \\
1.07\end{array}$ & $\begin{array}{l}2.06 \\
1.98\end{array}$ & $\begin{array}{r}0.21 \\
-1.04\end{array}$ & $\begin{array}{l}1.83 \\
1.77\end{array}$ \\
\hline$H$ f: suckler-fattener & $\begin{array}{c}0 \\
-0.6\end{array}$ & $\begin{array}{l}1.78 \\
1.72\end{array}$ & $\begin{array}{l}1.85 \\
1.81\end{array}$ & $\begin{array}{r}0.07 \\
-1.06\end{array}$ & $\begin{array}{l}1.82 \\
1.79\end{array}$ & $\begin{array}{l}1.78 \\
1.73\end{array}$ & $\begin{array}{l}2.06 \\
2.06\end{array}$ & $\begin{array}{r}0.08 \\
-1.20\end{array}$ & $\begin{array}{l}1.90 \\
1.84\end{array}$ \\
\hline $\begin{array}{l}\text { Simplified scheme } \\
\mathrm{Hg} \text { : global }\end{array}$ & $\begin{array}{c}0 \\
-0.6\end{array}$ & $\begin{array}{l}1.78 \\
1.57\end{array}$ & $\begin{array}{l}1.74 \\
1.57\end{array}$ & $\begin{array}{r}0.42 \\
-0.62\end{array}$ & $\begin{array}{l}1.64 \\
1.51\end{array}$ & $\begin{array}{l}2.10 \\
1.73\end{array}$ & $\begin{array}{l}2.04 \\
1.72\end{array}$ & $\begin{array}{r}0.78 \\
-0.45\end{array}$ & $\begin{array}{l}1.64 \\
1.52\end{array}$ \\
\hline$H$ s: suckler & $\begin{array}{c}0 \\
-0.6\end{array}$ & $\begin{array}{l}1.55 \\
1.11\end{array}$ & $\begin{array}{l}1.69 \\
1.47\end{array}$ & $\begin{array}{r}0.50 \\
-0.48\end{array}$ & $\begin{array}{l}1.61 \\
1.44\end{array}$ & $\begin{array}{l}2.03 \\
1.52\end{array}$ & $\begin{array}{l}1.95 \\
1.54\end{array}$ & $\begin{array}{r}0.91 \\
-0.19\end{array}$ & $\begin{array}{l}1.70 \\
1.38\end{array}$ \\
\hline$H$ f: suckler-fattener & $\begin{array}{c}0 \\
-0.6\end{array}$ & $\begin{array}{l}1.56 \\
1.45\end{array}$ & $\begin{array}{l}1.77 \\
1.60\end{array}$ & $\begin{array}{r}0.28 \\
-0.76\end{array}$ & $\begin{array}{l}1.66 \\
1.54\end{array}$ & $\begin{array}{l}1.66 \\
1.45\end{array}$ & $\begin{array}{l}2.09 \\
1.78\end{array}$ & $\begin{array}{r}0.52 \\
-0.69\end{array}$ & $\begin{array}{l}1.81 \\
1.56\end{array}$ \\
\hline
\end{tabular}




\section{CONCLUSION}

In this paper, only a section of the whole breeding scheme of a beef breed was considered, $i e$ the multistage selection of AI bulls. The next paper will present calculations of expected genetic gains for the selection nucleus. Current French beef bull selection programs, such as the Limousin progam, can provide important genetic gain for objectives concerning direct and maternal effects on growth. The scheme appears to be more efficient for a suckler-fattener's objective $(H \mathrm{f})$ than for a suckler's one $(H \mathrm{~s})$. A combined objective $H \mathrm{~g}$, which combines $H \mathrm{~s}$ and $H \mathrm{f}$, is taken as a reference for economic profit of the whole breed. Whatever the breeding objective considered to derive optimal selection thresholds, response in $H \mathrm{~g}$ is robust and is larger than responses in $H \mathrm{~s}$ and $H \mathrm{f}$. This is very satisfying from a national viewpoint. A slight negative genetic response in maternal effects is predicted, but is subject to uncertainty in preweaning genetic parameters. This is relatively disappointing since improving maternal effects will probably become more and more important. The trend towards extensification leads to an increased relative margin expected from improvement in maternal effects in comparison with improvement in direct effects.

A simplified scheme, keeping only a 'short performance test' and an on-farm progeny test with bull evaluation on maternal performance, would allow us to overcome this problem, at least if the true direct-maternal genetic correlation is not too far from its estimate (around -0.2). Moreover, it could induce an important gain in efficiency in $H \mathrm{~s}$ and $\mathrm{Hg}$ when on-farm progeny test capacity increases. Thus increasing on-farm progeny test capacity through the use of an animal model evaluation system applied to all beef recorded herds (Laloë and Ménissier, 1990) while simplifying the breeding scheme, might be considered as an efficient alternative to the current scheme.

However, a full evaluation of the efficiency of such selection schemes would require more complex models integrating feed efficiency, carcass composition, morphology and reproductive traits (such as fertility or ease of calving...). Indeed these traits are mainly evaluated in the 'long performance test' and in the station progeny test. However, as underlined by Newman et al (1992), our knowledge of genetic parameters is deficient in these areas. The lack of estimates is especially important for maternal performance and the relationship between direct and maternal effects (Ménissier and Frisch, 1992). Moreover, the necessity of obtaining accurate estimates of components of variance is underlined by the importance of variance in selection response due to uncertainty of genetic parameters when maternal effects have to be considered. This is essential for correctly ranking selection policies and predicting genetic gains.

\section{REFERENCES}

Aranyoss E, Kontro J (1991) Etude de la fonction économique de la phase naisseur et de la phase engraisseur en vue de l'orientation de la sélection de la race bovine Limousine. Mémoire de fin d'études de l'Institut national agronomique Paris-Grignon, France

Azzam SM, Nielsen MK (1987) Expected responses to index selection for direct and maternal additive effects of gestation length or birth date in beef cattle. J Anim Sci $64,357-365$ 
Belard JF, Baud G, Le Maréchal JY, Liénard G, Pizaine MC (1992) Production de jeunes bovins maigres ou engraissés en Limousin: campagne 90-91. Ser 158, CEMAGREF, France

Colleau JJ, Elsen JM (1988) Potentialities of embryo transfer for improvement of beef cattle and sheep productivity. $3^{e}$ Congrès mondial de reproduction et sélection des ovins et bovins à viande. Paris, 19-26 juin 1988. INRA, France, vol 1, 141-157

Doren PE, Shumway CR, Kothmann MM, Cartwright TC (1985) An economic evaluation of simulated biological production of beef cattle. J Anim Sci 60, 913-934

Drewry KJ, Brown CJ, Howea RS (1959) Relationships among factors associated with mothering ability in beef cattle. J Anim Sci 18, 938-946

Ducrocq V, Colleau JJ (1989) Optimum truncation points for independent culling level selection on a multivariate normal distribution, with an application to dairy cattle selection. Genet Sel Evol 21, 185-198

Foulley JL, Ollivier L (1986) A note on criteria of coherence for the parameters used to construct a selection index. J Anim Breed Genet 103, 81-86

Foulley JL, Sapa J (1982) The French evaluation programme for natural service beef bulls using AI sire progeny as herd ties. Digest 37, 64-68

Hanrahan JP (1976) Maternal effects and selection response with an application to sheep data. Anim Prod 22, 359-369

Hanset R (1981) Selection problems when antagonistic effects exist between production characteristics and calving difficulties. Livest Prod Sci 291-305

Harris DL (1964) Expected and predicted progress from index selection involving estimates of population parameters. Biometrics 20, 46-72

Harville DA (1977) Maximum likelihood approaches to variance component estimation and to related problems. J Am Stat Assoc 72, 320-338

INRA (1988) Alimentation des bovins, ovins et caprins (R Jarrige, ed), INRA, Paris, France

ITEB (1991) Troupeau allaitant : mode d'emploi (NE Grenet, ed), ITEB, Paris, France

Jeffery HB, Berg RT, Hardin RT (1971) Factors affecting preweaning performance in beef cattle. Can J Anim Sci 51, 561-577

Laloë D, Ménissier F (1990) Applications of an animal model on a national basis in the French beef cattle industry. 4th World Congr Genet Appl and Livest Prod. Edinburgh, UK, 22-27 July, vol 14, 327-329

Le Neindre P, Petit M, Tomassone R, Roux C (1976) Production laitière des vaches allaitantes et croissance de leurs veaux. I. Race Limousine. Ann Zootech 25, 221-224

Ménissier F, Foulley JL, Sapa J (1982) Selection of French beef breeds for purebreeding. 2nd World Cong Genet Appl Livest Prod, Madrid, Garsi, vol VIII, 314-324

Ménissier $F$ (1988) Selection of specialized beef breeds in France. $3^{e}$ congrès mondial de sélection des ovins et bovins à viande. Paris, 19-26 juin 1988. INRA, vol 2, 215-236

Ménissier F, Frisch JE (1992) Genetic improvement of beef cows. In: Beef Cattle Production. (R Jarrige, C Berange, eds), Elsevier, The Netherland, 55-85

Meyer K (1992) Bias and sampling covariances of estimates of variance components due to maternal effects. Genet Sel Evol 24, 487-509

Neville WE Jr (1962) Influence of dam's milk production and other factors on 120 and 240 day weight of Hereford calves. J Anim Sci 21, 315-320

Newman S, Morris CA, Baker RL, Nicoll GB (1992) Genetic improvement of beef cattle in New Zealand: breeding objective. Livest Prod Sci 32, 111-130

Phocas F, Colleau JJ, Ménissier F (1995) Expected efficiency of selection for growth in a French beef cattle breeding scheme. II. Prediction of asymptotic genetic gain in a heterogeneous population. Genet Sel Evol 27, 171-188 
Ponzoni RW, Newman S (1989) Developing breeding objectives for Australian beef cattle production. Anim Prod 49, 35-47

Renand G, Plasse D, Andersen BB (1992) Genetic improvement of cattle growth and carcass traits. In: Beef Cattle Production. (R Jarrige, C Beranger, eds), Elsevier, The Netherlands, 86-107

Sales J, Hill WG (1976a) Effect of sampling errors on efficiency of selection indices. I. Use of information from relatives for single trait improvement. Anim Prod 22, 1-17

Sales J, Hill WG (1976b) Effect of sampling errors on efficiency of selection indices. II. Use of information on associated traits for improvement of a single important trait. Anim Prod 23, 1-14

Searle SR, Casella G, McCulloch CE (1992) Variance Components. John Wiley \& Sons, New York, USA

Shi MJ, Laloë D, Ménissier F, Renand G (1993) Estimation of genetic parameters of preweaning performance in the French Limousin cattle breed. Genet Sel Evol 25, 177189

Tallis GM (1960) The sampling errors of estimated genetic regression coefficients and the errors of predicted genetic gains. Aust J Stat 2, 66-77

Van Vleck LD, Louis D, Miller JI (1977) Expected phenotypic response in weaning weight of beef calves from selection for direct and maternal genetic effects. J Anim Sci 44, 360-367

Woolliams JA, Meuwissen THE (1993) Decision rules and variance of response in breeding schemes. Anim Prod 56, 179-186

\section{APPENDIX I. Meaning of abbreviations used in tables and figures}

\section{Selection criteria}

W120: weight at $120 \mathrm{~d}$

W210: weight at $210 \mathrm{~d}$ or weaning weight

W400: weight at $400 \mathrm{~d}$

W500: weight at $500 \mathrm{~d}$ or final weight

$I_{\mathrm{s}}$ : optimum index combining average W500 of 30 bull's sons and average W120 of 20 calves of bull's daughters with maternal heritability of station W120 equal to 0.26 .

$I_{\mathrm{f} 1}$ :average $\mathrm{W} 210$ of 30 bull's sons.

$I_{\mathrm{f} 2}$ : optimal index for $\mathrm{Hi}$ combining average W210 of 30 bull's sons and average W120 of 20 calves of bull's daughters with maternal heritability of on-farm W120 equal to 0.16 .

Breeding values

A120: direct effects on W120

M120: maternal effects on W120

A210: direct effects on W210

M210: maternal effects on W210

A400: direct effects on W400

A500: direct effects on W500

\section{Selection objectives}

$H \mathrm{~g}$ : global objective

$H$ s: suckler objective

$H$ f: suckler-fattener objective 


\section{APPENDIX II. Derivation of breeding objectives}

\section{Derivation of margins for suckler herds}

- The economic margin $a_{\mathrm{f}_{1}}$ for direct effects on final weight (A500) in a suckler herd is equal to $0 \mathrm{FF}$, since calves are sold at weaning.

- The economic margin $a_{\mathrm{d}_{1}}$ for direct effects on weaning weight (A210) in a suckler herd is equal to $10.3 \mathrm{FF}$ per $\mathrm{kg}$.

This corresponds to the difference between the price per kilogram sold at weaning $(16.8 \mathrm{FF})$ and the feed cost $(6.5 \mathrm{FF})$ of one additional kilogram at weaning, due to direct genetic effects. This cost is assumed to amount to $5 \mathrm{~kg}$ of concentrate at the price of $1.3 \mathrm{FF} / \mathrm{kg}$. Recommendation for breeders (ITEB, 1991) is from 5 to $15 \mathrm{~kg}$ of concentrate per additional kilogram at weaning. The lowest value is considered in our calculations, because it seems to be the most likely choice for the breeder.

- The economic margin $a_{\mathrm{m} 1}$ for maternal effects on weaning weight (M210) in a suckler herd is equal to $13.8 \mathrm{FF}$ per $\mathrm{kg}$.

Maternal effects on W210 are supposed to be only due to dam's milk yield. Their marginal cost corresponds to the marginal cost of dam's feed intake. To get $1 \mathrm{~kg}$ heavier calves at weaning, dams should produce $8 \mathrm{~kg}$ more milk. This value corresponds to the ratio of the milk production to the gain of weight from birth to weaning in the Limousin breed. This may be an underestimate of the marginal number of kilograms of milk needed per additional kilogram over the average W210, which could be around $15 \mathrm{~kg}$ more milk. Estimates from 6 to $24 \mathrm{~kg}$ are observed in the literature (Drewry et al, 1959; Neville, 1962; Jeffery et al, 1971; Le Neindre et al, 1976). As uncertainty in the correct value is important, the same strategy as for calculation of $a_{\mathrm{d}_{1}}$ is considered. The minimum possible value is used, ie $8 \mathrm{~kg}$. The INRA feed recommendation (INRA, 1988) per additional $\mathrm{kg}$ of milk for a Limousin cow is 0.45 UFL (French energy units for cattle with low daily requirement, as lactating cow) and 0.3 UEB (French fill unit). Therefore, 3.6 UFL per additional kilogram of calf weaned are required, which corresponds to 2.4 UEB. The period from calving to weaning can be separated into 2 periods. During the first 3 months, animals are in cowsheds and cows are fed with a mixed ration of concentrate and forage. During the last 4 months, animals are on pasture. In order to simplify the calculation, it is assumed that during the 7 months, the diet is a mixed ration of concentrate and of a very digestible forage (value of buffer: $0.95 \mathrm{UEB}$ per $\mathrm{kg}$ of dry matter of forage). As forage is very digestible, a substitution rate of $-0.5 \mathrm{~kg}$ of forage per kilogram of concentrate must be taken into account. Under these assumptions, the 3.6 additional UFL can be provided by $1.5 \mathrm{~kg}$ dry matter of forage and $2.1 \mathrm{~kg}$ concentrate if their respective energy contents are $0.83 \mathrm{UFL}$ and 1.12 UFL per $\mathrm{kg}$. With a cost of forage equal to $0.2 \mathrm{FF}$ per $\mathrm{kg}$ of dry metter and a cost of concentrate equal to $1.3 \mathrm{FF}$ per $\mathrm{kg}$, the marginal cost of $1 \mathrm{~kg}$ change in maternal effects on weaning weight is $3.0 \mathrm{FF}$.

\section{Derivation of economic margins for suckler-fattening herds}

Let $y_{1}$ be the average W210, $y_{2}$ be the average W500 and $x$ be the daily postweaning gain, derived as $x=\left(y_{2}-y_{1}\right) / 290$. We denote by $W(t)$ the weight of the calf at a day $t$ between 210 and $500 \mathrm{~d}$. Assuming a linear growth during this period, $W(t)=y_{1}+x$ $(t-210)$.

Production costs $(c)$ of a calf sold at $500 \mathrm{~d}$ can be split in 2 parts: costs before weaning $\left(c_{1}\right)$ and costs after weaning $\left(c_{2}\right)$, such that $c=c_{1}+c_{2}$. Costs before weaning are assumed to be the same as for suckler herds (see above). Costs after weaning are derived from 
formulae established by INRA (1988) which calculate maintenance and growth costs at time $t\left(c_{2}(t)\right)$ as a function of growth rate $(x)$ and of metabolic weight $\left(W(t)^{0.75}\right)$ of the animal:

$$
c_{2}=\sum_{t=210}^{500} c_{2}(t) \quad \text { with } \quad c_{2}(t)=p\left(a+b x^{1.4}\right) W(t)^{0.75} \quad \text { in } \quad \mathrm{FF} / \mathrm{d}
$$

where $p$ is the price of 1 UFV (French energy units for growing cattle); $a$ and $b$ are coefficients calculated by INRA (1978) and depend on breed, sex and kind of production. For a young bull, $a$ and $b$ are respectively equal to 0.0502 and 0.0363 ; for a heifer, the corresponding values are 0.0472 and 0.0232 .

Following the data collected by Aranyoss and Kontro (1991), we assume that both heifers and young bulls are fed a mixed ration containing $5.4 \mathrm{~kg}$ dry matter of maize silage (with $0.8 \mathrm{UFV} / \mathrm{kg}$ ) and $2.1 \mathrm{~kg}$ concentrate (with $1.2 \mathrm{UFV} / \mathrm{kg}$ ). The cost of $1 \mathrm{~kg}$ dry matter of maize silage is $0.67 \mathrm{FF}$ and the cost of $1 \mathrm{~kg}$ concentrate is $1.11 \mathrm{FF}$. Finally, the price $p$ of $1 \mathrm{UFV}$ is $0.87 \mathrm{FF}$.

- The economic margin $a_{\mathrm{f} 2}$ for direct effects on final weight (A500) in a suckler-fattening herd is equal to $11.5 \mathrm{FF}$ per $\mathrm{kg}$.

The average price per $\mathrm{kg}$ of a calf sold at $500 \mathrm{~d}$ is $16.4 \mathrm{FF}$ (table I). The marginal cost of one unit change in A500 is $6.1 \mathrm{FF}$ for a male and $3.5 \mathrm{FF}$ for a female. Thus, the average marginal cost is $4.9 \mathrm{FF}$. It is calculated from the following equations:

$$
\begin{aligned}
\frac{\partial c}{\partial g_{2}} & =\frac{\partial c_{2}}{\partial x} \frac{\partial x}{\partial g_{2}}=\frac{1}{290} \frac{\partial c_{2}}{\partial x} \\
\frac{\partial c_{2}}{\partial x} & =\frac{\partial\left(\sum_{t=210}^{500} p\left(a+b x^{1.4}\right) W(t)^{0.75}\right)}{\partial x}=p\left[0.75\left(a+b x^{1.4}\right) S_{1}+1.4 b x^{1.4} S_{2}\right] \\
\text { with } S_{1} & =\sum_{j=0}^{290} j\left(y_{1}+j x\right)^{-0.25} \quad \text { and } S_{2}=\sum_{j=0}^{290}\left(y_{1}+j x\right)^{0.75}
\end{aligned}
$$

- Let $a_{\mathrm{d}_{2}}$ and $a_{\mathrm{m}_{2}}$ be the economic weights for respectively direct and maternal effects on weaning weight in a suckler-fattening herd; $a_{\mathrm{d}_{2}}=-4.8 \mathrm{FF}$ per $\mathrm{kg}$ and $a_{\mathrm{m}_{2}}=-1.3 \mathrm{FF}$ per $\mathrm{kg}$.

$$
a_{\mathrm{d}_{2}}=-\frac{\partial c}{\partial g_{1}}=-\left(6.5+\frac{\partial c_{2}}{\partial g_{1}}\right) \quad \text { and } \quad a_{\mathrm{m}_{2}}=-\frac{\partial c}{\partial g_{1}}=-\left(3.0+\frac{\partial c_{2}}{\partial g_{1}}\right)
$$

The marginal cost after weaning of one unit change in W210 (whatever the origin, either A210 or M210) is $-2.5 \mathrm{FF}$ for a male and $-0.9 \mathrm{FF}$ for a female. Thus, the average marginal cost is $-1.7 \mathrm{FF}$. For a given weight at $500 \mathrm{~d}$, a larger weaning weight leads to a smaller daily postweaning gain $(x)$ and thus, to a smaller food requirement for postweaning growth. 


\section{APPENDIX III. Derivation of the sampling covariance matrix of REML estimators}

\section{Model and notations}

$\mathbf{y}=\left(\begin{array}{l}\mathbf{y}_{11} \\ \mathbf{y}_{12} \\ \mathbf{y}_{21} \\ \mathbf{y}_{22}\end{array}\right)=\left[\begin{array}{lllll}\mathbf{1}_{n} & & & \\ & \mathbf{1}_{n} & & \\ & & \mathbf{1}_{n} & \\ & & \mathbf{1}_{n}\end{array}\right] \cdot\left(\begin{array}{l}\mu_{11} \\ \mu_{12} \\ \mu_{21} \\ \mu_{22}\end{array}\right)$
$+\left[\begin{array}{lllllll}\mathbf{Z}_{s} & \mathbf{Z}_{t} & \mathbf{Z}_{s} & \mathbf{Z}_{t} & & & \\ & & & & \mathbf{Z}_{s} & \mathbf{Z}_{t} & \\ & & & & & & \\ & & & & \end{array}\right] \cdot\left(\begin{array}{c}\mathbf{Z}_{s 1} \\ \mathbf{t}_{11} \\ \mathbf{s}_{12} \\ \mathbf{t}_{12} \\ \mathbf{s}_{21} \\ \mathbf{t}_{21} \\ \mathbf{s}_{22} \\ \mathbf{t}_{22}\end{array}\right)+\left(\begin{array}{l}\mathbf{e}_{11} \\ \mathbf{e}_{12} \\ \mathbf{e}_{21} \\ \mathbf{e}_{22}\end{array}\right)$

where, for trait $i$ ( $i=1$ is $\mathrm{W} 120 ; i=2$ is W210) and for the progeny $j$ th generation: $\mathbf{y}_{i j}$, vector of records; $\mu_{i j}$, mean of records taking into account the average genetic level of dams for each progeny generation; $\mathbf{e}_{i j}$, vector of residuals; $\mathbf{s}_{i j}$, vector of sire effects; $\mathbf{t}_{i j}$, vector of maternal grandsire (MGS) effects; $\mathbf{Z}_{\mathbf{s}}$, incidence matrix for sire effects; $\mathbf{Z}_{\mathbf{t}}$, incidence matrix for MGS effects.

Furthermore, we define $c$, the total number of traits; $n$, the number of records per trait and generation; $N$, the total number of records per trait $(N=2 n) ; p$, the number of bulls evaluated as sire and MGS; $m$, the number of records per bull $(n=p m) ; d$, the number of records per couple sire-MGS $(m=d p) ; \mathbf{X}$, the incidence matrix of fixed effects; $\mathbf{Z}$, the incidence matrix of genetic effects; $\mathbf{R}$, the residual variance-covariance matrix; $\mathbf{G}$, the genetic variance-covariance matrix; and $\mathbf{V}$, the phenotypic variance-covariance matrix.

The incidence matrices are $\mathbf{X}=\mathbf{I}_{2 c} \otimes \mathbf{1}_{n}, \mathbf{Z}=\mathbf{I}_{2 c} \otimes \mathbf{A}$ with $\mathbf{A}=\left(\mathbf{Z}_{\mathrm{s}} \mathbf{Z}_{\mathbf{t}}\right)$. The variance matrices are $\mathbf{R}=\mathbf{R}_{0} \otimes \mathbf{I}_{N}$ where $\mathbf{R}_{0}$ is a $c \times c$ matrix, $\mathbf{G}=\mathbf{G}_{0} \otimes \mathbf{I}_{p}$ where $\mathbf{G}_{0}$ is a $4 c \times 4 c$ matrix; $\mathbf{V}=\mathbf{Z}^{\prime} \mathbf{G} \mathbf{Z}+\mathbf{R} . \otimes$ stands for the direct product.

\section{General results}

The asymptotic sampling variance-covariance matrix $\operatorname{Var}(\widehat{\boldsymbol{\theta}})$ is given as the inverse of Fisher's information matrix $\mathbf{I}(\boldsymbol{\theta})$ (Searle et al, 1992);

$$
\operatorname{Var}(\widehat{\boldsymbol{\theta}})=\mathbf{I}(\boldsymbol{\theta})^{-1} \quad \text { with } \quad \mathbf{I}(\boldsymbol{\theta})=-\left\{E\left(\frac{\partial^{2} L}{\partial \theta_{i} \partial \theta_{j}}\right)\right\}_{i, j}
$$

where $L$ is the log likelihood of the multivariate normal density function,

with $E\left(\frac{\partial^{2} L}{\partial \theta_{i} \partial \theta_{j}}\right)=-\frac{1}{2} \operatorname{tr}\left[\mathbf{P} \frac{\partial \mathbf{V}}{\partial \theta_{i}} \mathbf{P} \frac{\partial \mathbf{V}}{\partial \theta_{j}}\right]$ and $\mathbf{P}=\mathbf{V}^{-1}-\mathbf{V}^{-1} \mathbf{X}\left(\mathbf{X}^{\prime} \mathbf{V}^{-1} \mathbf{X}\right)^{-1} \mathbf{X}^{\prime} \mathbf{V}^{-1}$

Another form of the $\mathbf{P}$ matrix has been derived by Harville (1977) and was used in our demonstration:

$\mathbf{P}=\mathbf{S}-\mathbf{S Z W} \mathbf{W}^{-1} \mathbf{Z}^{\prime} \mathbf{S}$ with $\mathbf{W}=\mathbf{Z}^{\prime} \mathbf{S Z}+\mathbf{G}^{-1}$ and $\mathbf{S}=\mathbf{R}^{-1}-\mathbf{R}^{-1} \mathbf{X}\left(\mathbf{X}^{\prime} \mathbf{R}^{-1} \mathbf{X}\right)^{-1} \mathbf{X}^{\prime} \mathbf{R}^{-1}$ 


\section{Simplified form of $S$ and $W$ matrices due to our structure of data}

Let us define $\mathbf{M}_{n}=\mathbf{I}_{n}-\frac{1}{n} \mathbf{J}_{n}$, an idempotent matrix. Then, $\mathbf{S}=\mathbf{R}_{0}^{-1} \otimes \mathbf{I}_{c} \otimes \mathbf{M}_{n}$

$$
\mathbf{W}=\mathbf{Z}^{\prime} \mathbf{S Z}+\mathbf{G}^{-1} \quad \text { with } \quad \mathbf{Z}^{\prime} \mathbf{S Z}=\left(\mathbf{R}_{\mathbf{0}}^{-1} \otimes \mathbf{I}_{c}\right) \otimes\left(\mathbf{A}^{\prime} \mathbf{M}_{n} \mathbf{A}\right)
$$

then $\mathbf{W}=\mathbf{m R}_{0}^{-1} \otimes \mathbf{I}_{c} \otimes \mathbf{I}_{2} \otimes \mathbf{M}_{p}+\mathbf{G}_{0}^{-1} \otimes \mathbf{I}_{p}$

thus $\mathbf{W}^{-1}=\mathbf{W}_{1} \otimes \mathbf{I}_{p}+\mathbf{W}_{2} \otimes \mathbf{J}_{p}$, where $\mathbf{W}_{1}$ and $\mathbf{W}_{2}$ can be easily calculated.

\section{Results of the derivation of traces}

Let $\mathbf{E}_{0}=m \mathbf{R}_{0}^{-1} \otimes \mathbf{I}_{2 c}$ and $\mathbf{W}_{0}=\mathbf{E}_{\mathbf{0}}-\mathbf{E}_{0} \mathbf{W}_{1} \mathbf{E}_{0}$

Between genetic components $\left(t_{1}\right)$

$$
t_{1}=(p-1) \cdot \operatorname{tr}\left[\mathbf{W}_{0} \mathbf{D}_{i} \mathbf{W}_{0} \mathbf{D}_{j}\right]
$$

because $\frac{\partial \mathbf{V}}{\partial \theta_{i}}=\mathbf{Z}^{\prime} \frac{\partial \mathbf{G}}{\partial \theta_{i}} \mathbf{Z}$ and $\frac{\partial \mathbf{G}}{\partial \theta_{i}}=\mathbf{D}_{\mathbf{i}} \otimes \mathbf{I}_{p}$ for any genetic variance components $\theta_{i}$.

Between genetic component and residual component $\left(t_{2}\right)$

$\frac{\partial \mathbf{V}}{\partial \theta_{i}}=\frac{\partial \mathbf{R}}{\partial \theta_{i}}=\frac{\partial \mathbf{R}_{\mathbf{0}}}{\partial \theta_{i}} \otimes \mathbf{I}_{p}$ for any residual variance component $\theta_{i}$

$t_{2}=(p-1) \cdot \operatorname{tr}\left[\mathbf{W}_{0} \mathbf{D}_{j} \mathbf{G}_{0}^{-1} \mathbf{W}_{1}\left(\left(\mathbf{R}_{0}^{-1} \frac{\partial \mathbf{R}_{0}}{\partial \theta_{i}}\right) \otimes \mathbf{I}_{2 c}\right)\right]$

\section{Between residual components $\left(t_{3}\right)$}

The following matrices are partitioned in $c^{2}$ blocks:

$\mathbf{R}^{-1}=\left\{\boldsymbol{\varepsilon}_{i j}\right\} \mathbf{S}=\left\{\mathbf{S}_{i j}\right\} \mathbf{S Z}=\left\{\mathbf{B}_{i j}\right\} \mathbf{W}^{-1}=\left\{\mathbf{W}_{i j}\right\}$

$\mathbf{P}=\left\{\mathbf{P}_{i j}\right\} \mathbf{C}=\left\{\mathbf{C}_{i j}\right\}=\mathbf{S Z W} \mathbf{W}^{-1} \mathbf{Z}^{\prime} \mathbf{S}$

$t_{3}$ is a sum of traces of products $\mathbf{P}_{i j} \mathbf{P}_{k 1}$ such that:

$$
\operatorname{tr}\left(\mathbf{P}_{i j} \mathbf{P}_{k l}\right)=\operatorname{tr}\left(\mathbf{S}_{i j} \mathbf{S}_{k l}\right)-\operatorname{tr}\left(\mathbf{S}_{i j} \mathbf{C}_{k l}\right)-\operatorname{tr}\left(\mathbf{C}_{i j} \mathbf{S}_{k l}\right)+\operatorname{tr}\left(\mathbf{C}_{i j} \mathbf{C}_{k l}\right)
$$

All these traces can be calculated as sums of traces of products of matrices of maximal size $2 c \times 2 c$. 